\title{
Recycling of Campus Waste Bicycles
}

\author{
Anqi $\mathrm{Ji}^{1, \mathrm{a}^{*}}$ and Jihui $\mathrm{Ma}^{2, \mathrm{~b}}$
}

${ }^{1}$ MOE Key Laboratory for Urban Transportation Complex Systems Theory and Technology, School of Traffic and Transportation, Beijing Jiaotong University, China

${ }^{2}$ Institute of Systems Engineering and Control, School of Traffic and Transportation, Beijing Jiaotong University, China

a16120762@bjtu.edu.cn, bjhma@bjtu.edu.cn

Keywords: Recycling; Campus public bicycle system; Sustainable; Economy; Environment

Abstract. In this paper, it is mainly about the recycling of campus waste bicycles. This paper takes Shandong University of Technology as an example, and obtains the different characteristics of different users through various methods such as questionnaire survey, community division and establishment of model. Based on this, a campus public bicycle system is established. The main job are to set the location and size of the site, establish a scheduling system and make recommendations for the pre-trial phase, which is good for sustainable development of economy and environment. Of course, this method may be more beneficial to the university where the city is without public bikes.

\section{Introduction}

In recent years, with the expansion of colleges and universities, the number of the campus bicycle also increases, at the same time there are also a lot of waste bicycles. In order to avoid the loss of resources, be convenient and safe for teachers and students to travel and beautify the campus, we can recycle these waste bicycles as campus public bike [1]. The public bicycle system mainly includes the monitoring system, maintenance system and scheduling system, which are responsible for monitoring, maintenance and scheduling [2, 3, 4].

If you want to take full advantage of these used bicycles, it is necessary to ensure that the system be built can operate well $[5,6]$. Therefore, in the construction of the system, we need to do pre-investigation [7]. The methods involved include the division of the university on land, questionnaires $[8,9]$. Of course, to complete the location and size of the site settings, as well as the late scheduling system also need us to analyze the previous data, build the relevant model. The operation mode of the public bicycle system is showed as Fig. 1

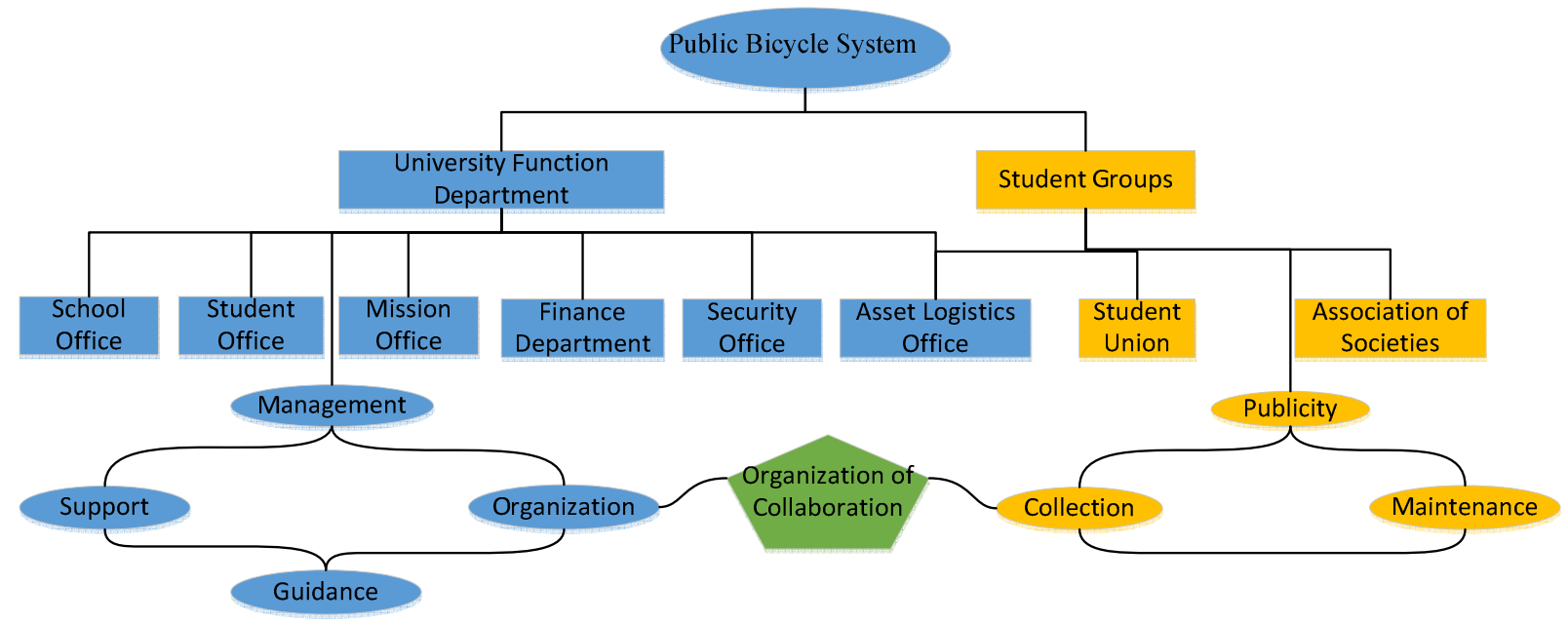

Figure 1. the service relationship in Shandong University of Technology 


\section{The Present Situation in Shandong University of Science and Technology}

When the term beginning, fresh students will buy all kinds of bicycles to save energy and reduce unnecessary waste of time. With the constant turnover of the students, old bicycles has been increasing. After an inquiry, there are many waste and dusty bicycles parking in front of the dormitories and library. Part of them are left by some graduates or the owners buy a new bike, there is also part of them are forgotten somewhere. The old bike has seriously damaged the overall image of the universities.

On the survey of the number of bicycles parked in front of the number of 8 and 9 apartments in the morning and evening for two days, summarized in the below tables.

Table 1 the number of bicycles parked in front of NO.8 and NO.9 apartments on May 17 and 18 in 2016

\begin{tabular}{|l|l|l|l|l|}
\hline \multicolumn{1}{|c|}{ Vehicle } & \multicolumn{4}{|c|}{ Date and Time } \\
\cline { 2 - 5 } & $\begin{array}{l}17 \text { th } \\
\text { Number }\end{array}$ & $\begin{array}{l}17 \text { th } \\
2: 00\end{array}$ & $\begin{array}{l}18 \text { th } \\
8: 00\end{array}$ & $\begin{array}{l}18 \text { th } \\
23: 00\end{array}$ \\
\hline NO.8 & 176 & 323 & 187 & 319 \\
\hline NO.9 & 194 & 378 & 211 & 383 \\
\hline
\end{tabular}

Although the date is individual, it is not incidental. It can be concluded from the two table that the utilization rate of bicycles is nearly about $50 \%$, which means that nearly half of the space and bicycles in front of each dormitory are wasted.

Table 2 the availability of bicycles parked in front of NO.8 and NO.9 apartments on May 17 and 18 in 2016

\begin{tabular}{|c|c|c|c|}
\hline Availability & & and 1 & \\
\hline Number & 17 th & 18th & Average \\
\hline NO.8 & 54.5 & 58.6 & 56.6 \\
\hline NO.9 & 51.3 & 55.1 & 53.2 \\
\hline
\end{tabular}

\section{Investigation of Public Bicycle System in Shandong University of Technology}

There are 20 colleges, 75 professional major, more than 32200 Undergraduate students and more than 2600 Graduate students. People need to comply with the rule of "two not and one observe", which is "not lock, not go out of university and observe the parked rule". Table 3 shows the distribution of the student. 
Table 3 distribution of different college students' apartments and the main teaching buildings

\begin{tabular}{|l|l|l|}
\hline College & Apartment(s) & Main teaching building(s) \\
\hline Chemistry & $7,8,13$ & $3,4,8,13$ \\
\hline Physical culture & 3 & $3,4,8,13$ \\
\hline Electrical & 5,11 & $1,3,4,8,13$ \\
\hline Law & 2 & $1,2,3,4,5,8$ \\
\hline Agriculture and Machinery & $2,13,15,16$ & $3,4,5,8,12$ \\
\hline Transportation & $8,9,14$ & $3,4,5,8,12$, Mechanical and traffic laboratory \\
\hline Mechanical & 8,11 & $3,4,5,8,12$, Mechanical and traffic laboratory \\
\hline Music & 3,4 & $3,4,5,8,10$ \\
\hline Art & 3,7 & $3,4,5,8,11$ \\
\hline Literature & 1 & $1,2,3,4,8$ \\
\hline Foreign Language & 3,4 & $3,4,5,8$ \\
\hline LU Tai & 1,2 & $1,3,4,5,8$ \\
\hline Computing Machinery & $6,8,11$ & $3,4,5,8,9$ \\
\hline Construction Engineering & $13,21,22$ & $3,4,5,8,12,15$ \\
\hline Mathematics & 17,18 & $3,4,5,8,15$ \\
\hline National Defense & 22 & Decided by different professional \\
\hline Resources and Environment & $14,16,20$ & $3,4,5,8,12,13$ \\
\hline Bio-science & 4 & $3,4,5,8.13$, \\
\hline Material Science & 16,19 & $3,4,5,8,13$ \\
\hline
\end{tabular}

There is a direct relationship between travel purpose and the land use function of college students [9]. Based on the analysis of the characteristics of time and space travel students, Shandong University of Technology is divided into the following 10 areas. In order to ensure the reliability of the survey results, combined with the "semi-open interviews" and "observation" [10], we can get the distribution characteristics on the time and space. The details are shown below Fig. 2 and Table 4. At the same time, the attract proportion of different destinations is showed in Fig. 3.

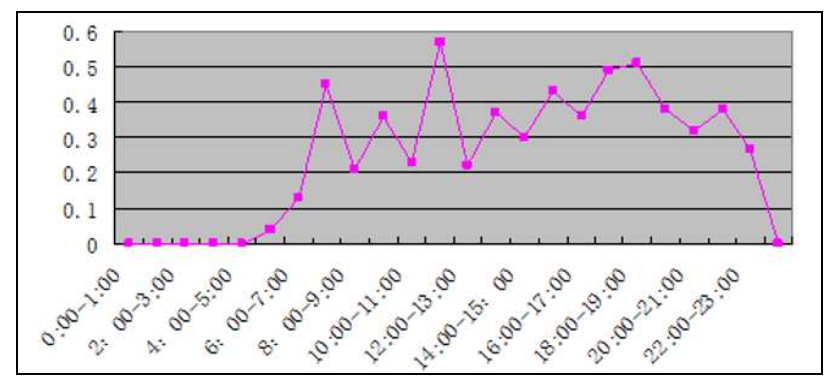

Figure 2. the distribution characteristics on the time

Table 4 the traffic amount of generation and attraction of each zone

\begin{tabular}{|l|l|l|l|l|}
\hline ID & $\mathbf{1}$ & $\mathbf{2}$ & $\mathbf{3}$ & Total \\
\hline 1 & & & & \\
\hline 2 & & & & \\
\hline 3 & & & 1400 & 1400 \\
\hline 4 & 1576 & & & 1576 \\
\hline 5 & 1200 & 3300 & 2349 & 6849 \\
\hline 6 & 1200 & 3300 & & 6849 \\
\hline 7 & 1335 & 2600 & 1900 & 5835 \\
\hline 8 & 1200 & & & 1200 \\
\hline 9 & 181 & 2073 & 1398 & 3652 \\
\hline 10 & & 2300 & & 2300 \\
\hline Total & 8047 & 13573 & 9396 & 31016 \\
\hline
\end{tabular}



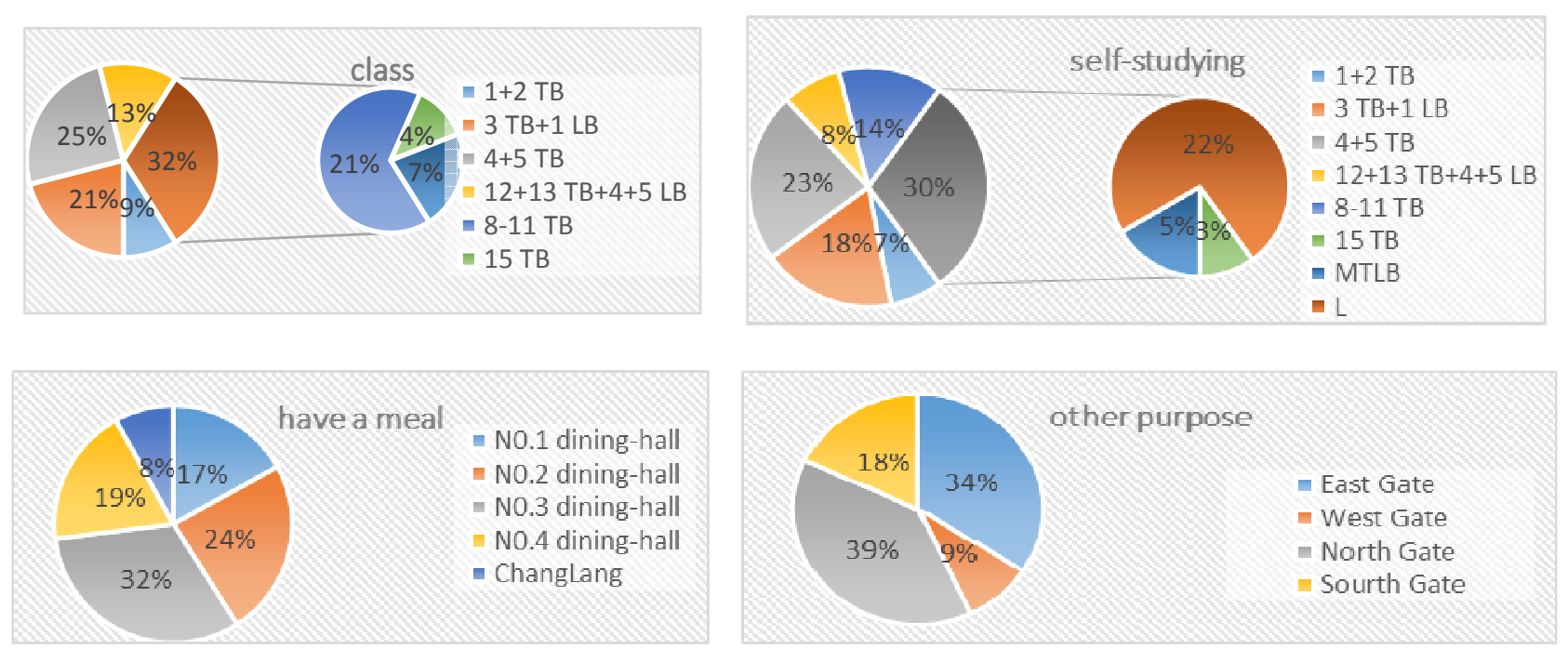

Figure 3. the attract proportion of different destinations

(TB: Teaching Building, LB: Laboratory Building, MTB: Mechanical and Traffic Laboratory Building)

\section{The Design of Public Bicycles System}

Site. According to the travel characteristics of the students, we can set up a site in each zone that is as close as possible to the main road so as to improve the convenience of students travel.

Due to the current public bicycle system in Shandong University of Technology is still in its infancy, coupled with the lack of publicity and protection of the school, resulting in a large number of public bicycles are in a state of failure or private. Therefore, most of the prediction methods are difficult to carry out $[11,12,13]$. For this reason, this paper proposes a rough and simple prediction method to optimize the public bicycle system of Shandong University of Technology.

According to the above analysis and data, establishing a model for the size of each site:

$c_{\mathrm{i}}=\max \left\{b_{j}\right\} \times N_{i} \times \mathrm{a}$

$C_{\mathrm{i}}$------The capacity of each site, $i=1,2,3 \ldots 10$

$N_{\mathrm{i}}$------The trip generation when $\mathrm{i}=1,2,3$

The trip attraction when $\mathrm{i}=4,5 \ldots 10$

$b_{j}$------The trip rate in the morning, afternoon and evening, $j=1,2,3, \operatorname{Max}\left\{b_{j}\right\}=b_{2}=38 \%$

s--------The constant, the percentage of people who don't have bikes but enjoy cycling, through investigation, it is $39 \%$

According to the above model, we can calculate the corresponding number of bicycles and the capacity of each zone, which provides a reference for the planning of the settlement area.

The following Table 5 and Table 6 show the location and size of each site. 
Table 5 the site location of public bike of Shandong University of Technology

\begin{tabular}{|l|l|l|}
\hline NO. & Scope & Site Locations \\
\hline 1 & NO.1-4 dormitory + NO.1-2 dining-hall & Between NO.1 and NO.2 dining-hall \\
\hline 2 & NO.5-12 dormitory + NO.3 dining-hall & Original position of NO.3 dining-hall \\
\hline 3 & $\begin{array}{l}\text { NO.13-22 dormitory + NO.4 dining-hall +NO.15 teaching } \\
\text { building }\end{array}$ & South Gate of NO.4 dining-hall \\
\hline 4 & NO.1-2 teaching building & The North side of NO. 2 teaching building \\
\hline 5 & NO.3 teaching building + NO.1 laboratory building & South Gate of NO.3 teaching building \\
\hline 6 & NO.4-5 teaching building & The North side of NO.4-5 teaching building \\
\hline 7 & NO.12-13 teaching building + NO.4-5 laboratory building & $\begin{array}{l}\text { Between NO.12 and NO.13 teaching } \\
\text { building }\end{array}$ \\
\hline 8 & NO.8-11 teaching building & $\begin{array}{l}\text { Between NO.10 and NO.11 teaching } \\
\text { building }\end{array}$ \\
\hline 9 & library & $\begin{array}{l}\text { North Gate of library } \\
\text { the eastern side of Mechanical and traffic } \\
\text { laboratory building }\end{array}$ \\
\hline 10 & Mechanical and traffic laboratory building & $\mid$ \\
\hline
\end{tabular}

Table 6 the site size of public bike in Shandong University of Technology

\begin{tabular}{|l|l|l|}
\hline No. & The number in the morning & the capacity \\
\hline 1 & 1193 & 1193 \\
\hline 2 & 2012 & 2012 \\
\hline 3 & 1392 & 1392 \\
\hline 4 & 0 & 234 \\
\hline 5 & 0 & 1015 \\
\hline 6 & 0 & 1015 \\
\hline 7 & 0 & 865 \\
\hline 8 & 0 & 178 \\
\hline 9 & 0 & 541 \\
\hline 10 & 0 & 341 \\
\hline
\end{tabular}

Scheduling System. In general, in every moment, a vehicle in the campus public bike system should be in the "in service" and "loan" and "stock" three states [14]. In the following situation occurs, we need to manage the bicycle scheduling: the site of the vehicle is in full load, zero load and vehicle malfunction; when users use no car available, use the failure happens, vehicle lost; enabling the vehicle in the warehouse, put idle vehicles in it.

The usage of public bicycle in campus most concentrated in the peak of adding and dropping classes, and in the morning rush, the users of the travel purpose is relatively single, traffic flow is more concentrated, and the demand of dormitory area and dining area is big. With the rhythm of the travel in campus, when the classes are over, or a day later, most concentrated in the teaching and self-study area, of course, there will be a part of scattered in other sites, which have failed and lost. If not in time to add or reduce the quantity of public bicycle as well as to maintain the fault for these sites, there will be demand exceeds supply and supply exceeding demand and so on, which can cause waste of resources of public bicycle. Therefore, according to the demand of each user in the morning, scheduling staff should be dispatching without delay.

By real-time monitoring the number of vehicles on each site, the available vehicles what can be learned in detail whether is in a state of saturation or inadequate. To public bicycle system on campus, the number of bicycles what is borrowed each time period can be predicted by some rules, which is on the basis of course situation of different grade and professional users $[15,16,17]$. In the long run, the related work of dispatcher can be appropriately reduced. Public bicycle scheduling process diagram is showed as followed.

Optimization Suggestions. From the point of management, students can be given a platform of social practice, which is organizing and managing campus public bicycles. On the premise of not 
delay learning, we can use the shift system, according to individual arrangement of spare time [18, 19].

From the point of repair and maintenance, the task can be given to logistics department (bicycle association) to ensure the campus bicycle system is able to run well.

From the point of students, if in use process, the malfunction of the bicycle occurs, students should consciously put the bike to the corresponding maintenance station, or to the specified fault vehicles station, which is convenient to repairmen.

\section{Summary}

Campus public bicycles can not only improve the use of the road and facilitate the travel of teachers and students, but also can recycle a large number of used bicycles, which can improve vehicle recycling, improve the campus appearance, save money. At the same time, it play a great role in "green travel, low-carbon life" [20].

All in all, we can achieve sustainable environmental and economic development through the recycling of campus waste bicycles.

\section{References}

[1] X.L. Wang and Yi Wan: The Border Economy and Culture, Vol. 14 (2013) No.3, p.114. (In Chinese)

[2] X.X. Wang: Transportation Enterprise Management, Vol. 1 (2010) No.5, p.18. (In Chinese)

[3] C.C. Liu: Research on the Design of Campus Bicycle Parking Leasing System (MS., Beijing Institute of Technology, China 2015), p.24. (In Chinese)

[4] Y.M. Zhao: Research on Campus Public Service Design in Innovative Universities (MS., Jiangnan University, China 2013), p.7. (In Chinese)

[5] L.N Liu, R. Huang, Y. Lin and H. Zhao: the Chinese and Foreign Entrepreneurs, Vol. 7 (2014) No.20, p.114. (In Chinese)

[6] B. Huang and M.X. Shen: Applied Mechanics and Materials, Vols. 178-181 (2012) No.5, p.1951.

[7] M. Zhang: Research on Campus Traffic System Design in Colleges and Universities (MS., Nanchang University, China 2007), p.10. (In Chinese)

[8] Y.X. Cao: Study on the Planning and Design of University Campus (MS., Shandong University, China 2010), p.32. (In Chinese)

[9] J.B. Xu and Z.Y. Zhang: Procedia-social and Behavioral Sciences, Vol.43 (2012) No.5, p.550. (In Chinese)

[10]G.X. Yao: Study on Sampling Technology and Data Analysis of Urban Resident Trip (MS., Chang'an University, China 2010), p.11. (In Chinese)

[11] Y.Y. Feng: Research on Layout Method of Public Bicycle Lease Point (MS., Chang'an University, China 2014), p.36. (In Chinese)

[12]N. Bao: Study on Decision - Making and Dispatching Model of Urban Public Bicycle Rental Point (MS., Chang'an University, China 2012), p.23. (In Chinese)

[13]H.X. Luo: Study on Site Selection Method of Urban Public Bicycle Leasing (MS., Beijing Jiaotong University, China 2013), p.27. (In Chinese)

[14]L.X. Ye: Research on Urban Public Bicycle Dispatching System (MS., Nanjing University of Science and Technology, China 2013), p.19. (In Chinese)

[15] S.S. Yang, P.F. Chen and L.L. Zhao: New West, Vol.3 (2014) No.3, p.58. (In Chinese)

[16]J. Qian: Urban Public Bicycle Rental Point Borrowing Demand Forecasting and Analysis (MS., Chang'an University, China 2015), p.22. (In Chinese)

[17]Q. Qin: Research on Scheduling Problem of Public Bicycle Rental System (MS., Beijing Jiaotong University, China 2013), p.14. (In Chinese)

[18]C. Zheng, X.F. Wang and C. Wu: Trans Tech Publications, Vols. 734-737 (2013), p.1590. 
[19]J.X. Li: Research on Optimization of Public Bicycle Scheduling (MS., Changsha University of Science and Technology, China 2013) p.18. (In Chinese)

[20]Bélanger-Gravel Ariane, Gauvin Lise, Fuller Daniel and Drouin Louis: Journal of health psychology, Vol.12 (1016) No., p.944. 